\title{
Surgical outcomes of long spinal fusions for scoliosis in adult patients with rheumatoid arthritis
}

\author{
Addisu Mesfin, MD, ${ }^{1}$ Mostafa H. El Dafrawy, MD, ${ }^{1}$ Amit Jain, MD, ${ }^{1}$ Hamid Hassanzadeh, MD, ${ }^{2}$ \\ John P. Kostuik, MD, ${ }^{1}$ Mesfin A. Lemma, MD, ${ }^{1}$ and Khaled M. Kebaish, MD' \\ 'Department of Orthopaedic Surgery, Johns Hopkins University, Baltimore, Maryland; and 2Department of Orthopaedic Surgery, \\ University of Virginia, Charlottesville, Virginia
}

\begin{abstract}
OBJECT In this study, the authors compared outcomes and complications in patients with and without rheumatoid arthritis (RA) who underwent surgery for spinal deformity.

METHODS The authors searched the Johns Hopkins University database for patients with RA (Group RA) and without RA (Group NoRA) who underwent long spinal fusion for scoliosis by 3 surgeons at 1 institution from 2000 through 2012. Groups RA and NoRA each had 14 patients who were well matched with regard to sex (13 women/1 man and 12 women/2 men, respectively), age (mean 66.3 years [range 40.5-81.9 years] and 67.6 years [range 51-81 years]), follow-up duration (mean 35.4 months [range 1-87 months] and 44 months [range 24-51 months]), and number of primary ( 8 and 8 ) and revision ( 6 and 6 ) surgeries. Surgical outcomes, invasiveness scores, and complications were compared between the groups using the nonpaired Student t-test $(p<0.05)$.

RESULTS For Groups RA and NoRA, there were no significant differences in the average number of levels fused (10.6 [range 9-17] vs 10.3 [range 7-17], respectively; $p=0.4$ ), the average estimated blood loss (2892 $\mathrm{ml}$ [range 1300-5000 $\mathrm{ml}$ ] vs $3100 \mathrm{ml}$ [range $1700-5200 \mathrm{ml}$ ]; $p=0.73)$, or the average invasiveness score (35.5 [range 21-51] vs 34.5 [range $23-58$ ]; $p=0.8$ ). However, in Group RA, the number of major complications was significantly higher (23 vs $11 ; p<$ 0.001 ), the number of secondary procedures was significantly higher (14 vs $6 ; p<0.001)$, and the number of minor complications was significantly lower (4 vs $12 ; p<0.001$ ) than those in Group NoRA.
\end{abstract}

CONCLUSIONS Long spinal fusion in patients with RA is associated with higher rates of major complications and secondary procedures than in patients without RA.

http://thejns.org/doi/abs/10.3171/2014.10.SPINE14365

KEY WORDS long spinal fusion; rheumatoid arthritis; scoliosis; surgical outcome; complications; deformity

$\mathrm{R}$ HEUMATOID arthritis (RA) is an inflammatory autoimmune condition characterized by debilitating and destructive polyarthritis of the small and large joints. It affects as much as $0.5 \%-1.5 \%$ of the US population and afflicts women more than men. ${ }^{20}$ It is associated with high morbidity and mortality rates, which are as high as $35 \% .{ }^{35}$ It often presents as pain and swelling of the proximal interphalangeal and metacarpophalangeal joints, wrists, and ankles, but in advanced forms, it can lead to the destruction of major joints, including the knee, hip, shoulder, and elbow. ${ }^{21,22,30,36}$

Most of the literature about RA complications in the spine has focused on the cervical spine (including atlantoaxial subluxation, atlantoaxial impaction, and subaxial subluxation). $1,4,7,9,10,18,25,27-29,31$ There have been few reports on RA-associated lumbar spine abnormalities, and in the reports that do exist, the focus was on spondylitis, degenerative spondylolisthesis, subluxation, disc space narrowing, apophyseal erosions, facet erosions, compression fractures, and stenosis. ${ }^{14-17,19,33,37}$ There has also been a dearth of reports focusing on the clinical outcomes of patients with RA who underwent lumbar spine surgery, ${ }^{8}$ and only 2 reports focused on patients with RA with scoliosis, both of which concerned juvenile RA. ${ }^{26,32}$ Our goal was to com- 
pare surgical outcomes and complications in patients with and without RA who underwent surgery for spinal deformity.

\section{Methods \\ Patient Population}

After we obtained approval from the Johns Hopkins University (JHU) institutional review board, patients with RA and spinal deformity who underwent surgery between 2000 and 2012 by 3 surgeons at JHU were identified. Inclusion criteria were a diagnosis of RA, fusion of 7 or more spinal levels, and a diagnosis of degenerative or idiopathic scoliosis. Overall, 14 patients with RA met the inclusion criteria (Table 1). We compared these patients (Group RA) against a cohort without RA (Group NoRA). The patients in Group NoRA were selected on the basis of a diagnosis of spinal deformity, lack of RA diagnosis, number of levels fused equivalent to that of patients in Group RA, and age similar to that of patients in Group RA. With regard to fusion level, 12 of the 14 patients in Group RA had fusion to the pelvis (1 ended at L-5, and 1 ended at L-1), whereas 13 of the 14 patients in Group NoRA had fusion to the pelvis (1 ended at L-5). We matched the patients as closely as possible according to sex, age, and levels fused. A combination of iliac crest bone graft and local autograft was used (Table 1). Bone morphogenetic protein-2 was not used in these cases.

A retrospective evaluation of a prospectively maintained database was performed by an independent surgeon who was not involved in the initial surgery or aftercare of the patients. The data collected included patient demographics (age, sex, race, diagnosis, and comorbidities), surgical demographics (procedure type, operative time, estimated blood loss, and number of levels fused), and outcome factors (complications and need for secondary procedures). Complications were classified as major or minor according to previously published criteria. ${ }^{11} \mathrm{We}$ also compared the 2 groups in terms of invasiveness of the surgery, as defined by Mirza et al..$^{24}$ and elaborated by Cizik et al. ${ }^{5}$

There were no significant differences between the groups in terms of average age, sex, race, diagnosis, type of procedure (primary vs revision), type of surgery (e.g., posterior instrumentation; Fig. 1), estimated blood loss, number of levels fused, length of hospitalization, or length of follow-up (Table 2). Six patients in Group RA and 8 patients in Group NoRA had anterior column support. There was only 1 notable difference between the groups in terms of demographic, surgical, or hospitalization data: Group NoRA had significantly more patients with kyphosis superimposed on degenerative scoliosis than did Group RA ( 7 vs 3 , respectively; $\mathrm{p}<0.02$ ).

There were no significant differences between the groups in regard to comorbidities such as diabetes $(\mathrm{p}=$ $0.28)$ and smoking $(\mathrm{p}=0.16)$. In Group RA, comorbidities included Type 2 diabetes mellitus ( 1 patient), hypertension (9 patients), coronary artery disease (3 patients), and current tobacco smoking (1 patient). Their RA medications included oral steroids (11 patients), disease-modifying antirheumatic medications (9 patients), and a biological disease-modifying antirheumatic medication (2 patients).
In Group NoRA, comorbidities included hypertension (8 patients), diabetes mellitus (1 patient), and current tobacco smoking (2 patients).

\section{Statistical Analysis}

The nonpaired Student t-test was used for comparison of the variables. Significance was set at a p value of $<0.05$, and commercially available statistical software (SAS 9.2) was used.

\section{Results \\ Major and Minor Complications}

Significantly more major complications occurred in Group RA than in Group NoRA (23 vs 11, respectively; $\mathrm{p}<0.001$; Table 3). In Group RA, 2 epidural hematomas required evacuation (1 on postoperative Day 2 in 1 patient and 1 on postoperative Day 7 in another patient), and 1 patient with respiratory failure required reintubation and subsequent tracheostomy. One patient whose respiratory failure was a result of a massive pulmonary embolism died on postoperative Day 9 secondary to respiratory failure. Another patient developed a deep wound infection (Clostridium difficile), became septic, and subsequently died as a result of respiratory failure. In Group NoRA, there were 11 major complications; 6 were managed medically, and 5 were managed with secondary procedures, including irrigation and debridement of a deep wound infection, surgery for pseudarthrosis, extension of fusions for proximal junctional kyphosis, and decompression for nerve root symptoms.

There were significantly fewer minor complications in Group RA than in Group NoRA (4 vs 12, respectively; $p$ $<0.001$; Table 3).

\section{Secondary Procedures}

Secondary procedures were required by significantly more patients in Group RA than in Group NoRA (14 vs 6 , respectively; $p<0.001$; Table 3). In Group RA, the secondary procedures included 6 reinstrumentations, 1 laminectomy, 2 epidural hematoma evacuations, and 5 irrigations and debridements for deep wound infections (serial irrigations and debridements for the same patient were counted individually). In Group NoRA, there were 2 reinstrumentations, 1 decompression, 1 irrigation and debridement for a deep wound infection, 1 extension of fusion to manage proximal junctional kyphosis, and 1 interventional radiology procedure to remove a broken central line wire.

\section{Invasiveness Score}

The index of surgical invasiveness ${ }^{5,24}$ was 35.5 for Group RA and 34.5 for Group NoRA. There was no significant difference $(\mathrm{p}=0.8)$ between the 2 groups in terms of surgical invasiveness.

\section{Discussion}

Abnormalities of the thoracolumbar spine in patients with RA have not been well studied. Our 13-year series of adult patients with RA who underwent thoracolumbar long fusions for spinal deformity has shown that patients 


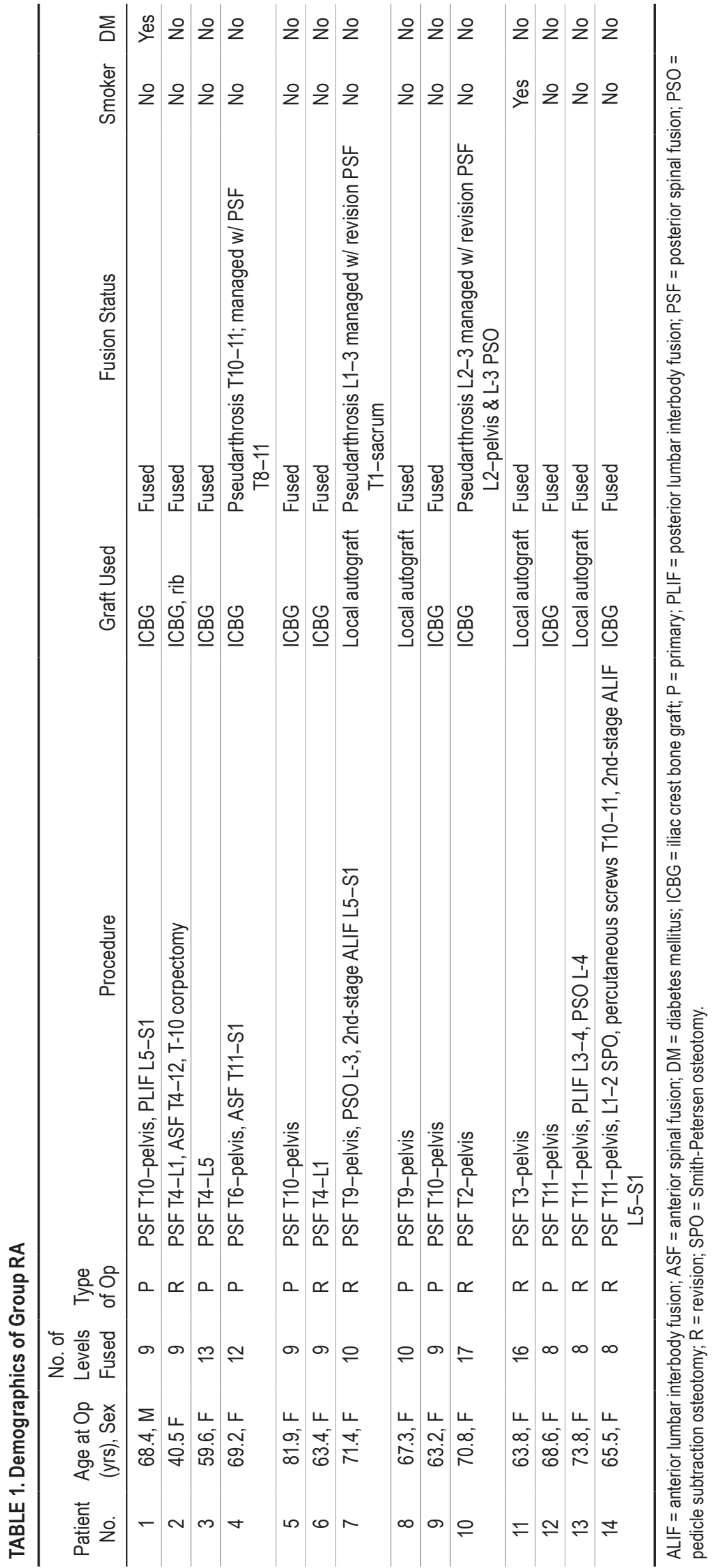



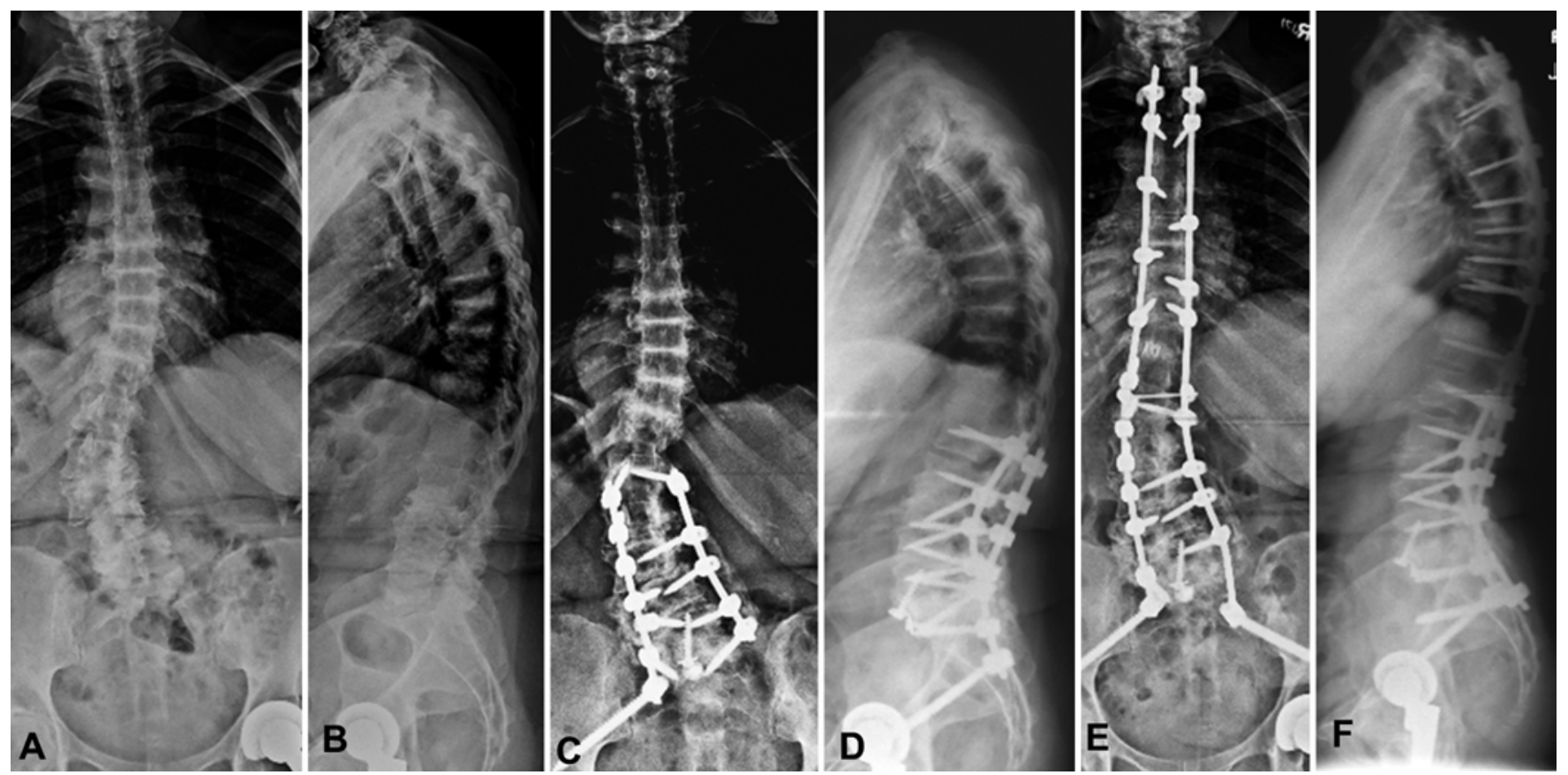

FIG. 1. Patient 10. A 71-year-old woman with RA and scoliosis (A and $B$ ) had a history of $L 1$-ilium posterior spinal fusion with instrumentation, L3-5 laminectomy, and L5-S1 anterior lumbar interbody fusion (C and D). At follow-up, she had stenosis at T9-10 and T10-11 that required revision of instrumentation and extension of the fusion to T-2, vertebral column resection of T-11, and interbody fusion ( $E$ and $F$ ). At the latest follow-up, the patient continued to be pain free.

with RA and spinal deformity had higher rates of major complications and secondary procedures than did patients with spinal deformity without RA. In terms of surgery duration, we did not find any differences between the 2 groups. Increased duration of surgery has been attributed to increased complications such as infection. However, in our well-matched cohort, the duration of surgery did not seem to be a factor in the higher rate of complications in Group RA. Group NoRA had a significantly higher rate of minor complications than Group RA, but these complications did not translate into longer hospital stays.
Studies in the literature that addressed the surgical treatment of patients with RA focused on strategies for treating cervical spine abnormalities. ${ }^{2,3,6,12,34}$ The mortality rates for patients who underwent these surgeries ranged from $5 \%$ to $10 \%$, and complication rates ranged from $19 \%$ to $39 \% .3,6$

A few studies have reported elevated rates of complications in patients with RA who underwent lumbar spine surgery. For example, Crawford et al. ${ }^{8}$ reported on 19 patients with RA who underwent instrumented posterolateral lumbar fusion, which resulted in a $37 \%$ complication

TABLE 2. Demographic, surgical, and hospitalization data

\begin{tabular}{lccc}
\hline \multicolumn{1}{c}{ Characteristic } & Group RA $(\mathrm{n}=14)$ & Group NoRA $(\mathrm{n}=14)$ & $\mathrm{p}$ Value \\
\hline Female/male ratio & $13: 1$ & $12: 2$ & 0.28 \\
\hline Race (Caucasian/African American) ratio & $13: 1$ & $14: 0$ & 0.16 \\
\hline Mean age in yrs (range) & $66.3(40.5-81.9)$ & $67.6(51-81)$ & 0.69 \\
\hline No. w/ adult degenerative scoliosis & 14 & 14 & 0.15 \\
\hline w/ superimposed lumbar stenosis & 12 & 10 & $<0.02^{*}$ \\
\hline w/ kyphosis & 3 & 7 & $\mathrm{NA}$ \\
\hline Primary/revision procedure ratio & $8: 6$ & $3: 6$ & 0.73 \\
\hline Mean EBL in ml (range) & $2892(1300-5000)$ & $5100(1700-5200)$ & 0.34 \\
\hline Mean length of op in mins (range) & $476(280-540)$ & 10.3 & 0.4 \\
\hline Mean no. of levels fused & 10.6 & $10.3(5-17)$ & 0.26 \\
\hline Mean (range) length of hospitalization (days) & $12.6(5-55)$ & $44.3(24-51)$ & 0.16 \\
\hline Mean LOS in mos (range) & $35.4(0.03-88.5)$ & $34.5(23-58)$ & 0.8 \\
\hline Mean invasiveness score (range) & $35.5(21-51)$ & & \\
\hline
\end{tabular}

$\mathrm{EBL}=$ estimated blood loss; $\mathrm{LOS}=$ length of stay; NA = not applicable

* Statistically significant. 
TABLE 3. Numbers of major complications, minor complications, and secondary procedures

\begin{tabular}{|c|c|c|}
\hline Parameter* & $\begin{array}{c}\text { Group } \\
\text { RA }\end{array}$ & $\begin{array}{l}\text { Group } \\
\text { NoRA }\end{array}$ \\
\hline Major complications & 23 & 11 \\
\hline Acute renal failure & 0 & 1 \\
\hline Arrhythmia & 1 & 1 \\
\hline Bilateral L- 5 pars fractures & 1 & 0 \\
\hline Clostridium difficile infection & 1 & 0 \\
\hline Deep wound infection & 3 & 1 \\
\hline Death & 2 & 0 \\
\hline Epidural hematoma & 2 & 0 \\
\hline Instrumentation failure & 1 & 0 \\
\hline Neurological deficit & 1 & 1 \\
\hline Proximal junctional kyphosis & 3 & 4 \\
\hline Pseudarthrosis & 3 & 1 \\
\hline Pulmonary embolism & 1 & 1 \\
\hline Respiratory complications & 3 & 0 \\
\hline Sepsis & 1 & 0 \\
\hline Severe blood loss requiring surgical staging & 0 & 1 \\
\hline Minor complications & 4 & 12 \\
\hline Atrial fibrillation (recurrence) & 0 & 1 \\
\hline lleus & 0 & 4 \\
\hline Incidental durotomies & 2 & 2 \\
\hline Superficial wound infection & 1 & 2 \\
\hline Urinary tract infection & 1 & 2 \\
\hline Delirium & 0 & 1 \\
\hline Secondary procedures & 14 & 6 \\
\hline Epidural hematoma evacuation & 2 & 0 \\
\hline Irrigation \& debridement (for deep wound infection) & 5 & 1 \\
\hline L-2 PSO \& revision L1-S1 PSF & 1 & 0 \\
\hline T9-10 laminectomy & 1 & 0 \\
\hline L1-sacrum PSF w/ L-2 PSO & 1 & 0 \\
\hline $\begin{array}{l}\text { ALIF at L5-S1 \& extension of instrumentation to } \\
\text { the pelvis (for bilat L-5 pars fractures) }\end{array}$ & 1 & 0 \\
\hline $\begin{array}{l}\text { T9-10 posterior osteotomy \& T3-11 PSF (for } \\
\text { T9-10 PJK) }\end{array}$ & 1 & 0 \\
\hline PJK at T-10 requiring extension of fusion to T-3 & 1 & 0 \\
\hline PJK at T-3 requiring extension of fusion to $\mathrm{C}-5$ & 1 & 0 \\
\hline $\begin{array}{l}\text { Decompression of rt L-4 nerve root after compres- } \\
\text { sion fracture \& nerve root impingement }\end{array}$ & 0 & 1 \\
\hline Extension of the fusion to C-3 (for PJK) & 0 & 1 \\
\hline $\begin{array}{l}\text { Revision w/ interbody fusions (for broken rods \& } \\
\text { pseudarthrosis) }\end{array}$ & 0 & 1 \\
\hline PJK at T-10 requiring extension of fusion to T-3 & 0 & 1 \\
\hline $\begin{array}{l}\text { Interventional radiological procedure to remove } \\
\text { broken central line wire }\end{array}$ & 0 & 1 \\
\hline
\end{tabular}

PJK = proximal junctional kyphosis.

* Groups RA and NoRA were significantly different in regard to all 3 parameters. rate; these complications included deep wound infections, pseudarthrosis, implant complications, and adjacent segment degeneration. Similarly, a Japanese group studying posterior lumbar interbody fusion in 7 patients with RA with severe low back pain and/or cauda equina symptoms reported 10 complications, including collapse of adjacent vertebrae, instability of adjacent levels, migration of a pedicle screw, collapse of grafted bone, and wound infections..$^{16}$

We think certain factors contribute to the high complication rates associated with surgery for spinal deformity in patients with RA. First, patients with RA are often relatively osteoporotic. Lawrence et al. ${ }^{19}$ first identified increased osteoporosis in the lumbar spine of patients with RA in 1964. They saw osteoporosis in association with subluxation, disk narrowing without vertebral osteophytosis, and apophyseal erosions much more commonly in patients with RA than in the general population. ${ }^{19}$ Other groups have also confirmed the presence of osteoporosis..$^{14,17}$ It is likely that the complications related to instrumentation, such as junctional failure and pseudarthrosis, are associated with the osteoporosis. Second, patients with RA are often immunocompromised as a result of the disease and of treatment with steroids and disease-modifying antirheumatic medications. ${ }^{13}$ In our study, 11 of 14 patients were chronically on steroids and at increased risk of secondary osteoporosis. The high risk of perioperative infections in these patients likely arises from these medications. Similarly, difficulties in wound healing can arise from the relative immunodeficiency in patients with RA. Both of these effects likely contributed to the high complication rates that we found in our study. Third, long fusions for deformity correction in adults also carry a baseline complication risk as high as $49 \% .{ }^{38}$ However, in our study, Groups RA and NoRA had similar levels fused, and Group RA still had significantly higher rates of major complications (23 vs 11 , respectively) and secondary procedures (14 vs 6 , respectively).

Mirza et al. ${ }^{24}$ proposed the invasiveness index as a means of quantifying the complexity of spine procedures so that adequate comparisons between surgical procedures and other factors that are evaluated (estimated blood loss, length of surgery, and length of hospitalization) can be made. In a series of 1532 patients who had undergone spinal surgery, an invasiveness score of greater than 21 $(\mathrm{p}<0.01)$ was found to be a risk factor for surgical site infection. ${ }^{5}$ In that same study, invasiveness scores were divided into 6 groups $(1-5,6-10,11-15,16-20,21-25$, and $>25$ ). The invasiveness scores in our study, 35.5 (Group RA) and 34.5 (Group NoRA), placed both groups in the most invasive surgical category. This finding is to be expected, because long-construct spinal deformity surgeries are invasive. However, no difference in the invasiveness scores of these 2 groups was present, which is indicative of a well-matched cohort.

To mitigate the increased risk of complications in spinal deformity surgery for patients with RA, we made certain changes to our presurgical and postsurgical protocols. Because most patients are chronically on steroids and have secondary osteoporosis, we recommend starting them on Teriparatide (Forteo Eli Lilly), an anabolic agent for osteoporosis, preoperatively and having them continue it 
postoperatively. This protocol is performed in consultation with an endocrinologist or a bone health center. We also routinely check vitamin D levels and supplement vitamin D insufficiency or deficiency preoperatively. Intraoperatively, we administer tranexamic acid (to patients with no contraindications) at the beginning of the case to decrease intraoperative blood loss. We also use intrawound vancomycin powder before incision closure to decrease the risk of postsurgical infections.

There are some limitations to our study. Health quality-of-life data, such as Scoliosis Research Society-30 and 36-Item Short Form Health Survey or visual analog scale pain scores, were not reported for our patients; we did not start collecting such outcome questionnaires until halfway through the study period. We also do not report the radiographic outcomes in our patients. Because most patients were being managed for degenerative lumbar scoliosis and stenosis, the lack of radiographic outcomes may not be as critical as it is for patients being treated for adolescent idiopathic scoliosis, for whom the primary goal is correction of the spinal deformity. It also would have been helpful if we had had baseline bone mineral density values for our patients with RA to compare with those of the patients without RA. Last, a larger number of patients with RA would have helped us to better assess the rate of complications in this group. However, even in our center, which is a high-volume spinal deformity referral center, only 14 patients with long fusions were identified over the study period. However, we believe that this matched series highlights and confirms many anecdotal findings noted by spinal deformity surgeons regarding higher complication rates in patients with RA and will help in counseling such patients who are planning to undergo spinal deformity surgery. In addition, preoperative dual-energy $\mathrm{x}$-ray absorptiometry scan data for quantifying osteoporosis/osteopenia in the control and RA groups would have been useful for studying further the link between poor bone mineral density and complications. We realize that statistical significance in a small study sample is not as robust as that in a larger sample. We hope that our study provides an impetus for additional research on thoracolumbar deformity surgery in patients with RA through multi-institutional studies. The report of a recent cross-sectional prevalence study on lumbar scoliosis in Japanese patients with RA noted that $32 \%$ of them had lumbar scoliosis. ${ }^{23}$ Dual-energy $x-$ ray absorptiometry was used to diagnose the scoliosis, and increased age seemed to be a risk factor for scoliosis. Therefore, enrolling patients with RA who are undergoing thoracolumbar surgery in a multicenter manner is feasible.

\section{Conclusions}

Patients with RA experience a higher rate of major complications and secondary procedures after undergoing long spinal fusion for deformity correction than do patients without RA. We suspect that the high complication rates are caused by a combination of poor bone quality and a weakened immune system. Surgeons should counsel their patients with RA and spinal deformity to make them aware that they could experience higher rates of complications and secondary procedures than patients without RA.

\section{References}

1. Boden SD, Dodge LD, Bohlman HH, Rechtine GR: Rheumatoid arthritis of the cervical spine. A long-term analysis with predictors of paralysis and recovery. J Bone Joint Surg Am 75:1282-1297, 1993

2. Casey AT, Crockard HA, Bland JM, Stevens J, Moskovich R, Ransford AO: Surgery on the rheumatoid cervical spine for the non-ambulant myelopathic patient-too much, too late? Lancet 347:1004-1007, 1996

3. Casey AT, Crockard HA, Stevens J: Vertical translocation. Part II. Outcomes after surgical treatment of rheumatoid cervical myelopathy. J Neurosurg 87:863-869, 1997

4. Castro S, Verstraete K, Mielants H, Vanderstraeten G, de Reuck J, Veys EM: Cervical spine involvement in rheumatoid arthritis: a clinical, neurological and radiological evaluation. Clin Exp Rheumatol 12:369-374, 1994

5. Cizik AM, Lee MJ, Martin BI, Bransford RJ, Bellabarba C, Chapman JR, et al: Using the spine surgical invasiveness index to identify risk of surgical site infection: a multivariate analysis. J Bone Joint Surg Am 94:335-342, 2012

6. Clark CR, Goetz DD, Menezes AH: Arthrodesis of the cervical spine in rheumatoid arthritis. J Bone Joint Surg Am 71:381-392, 1989

7. Conlon PW, Isdale IC, Rose BS: Rheumatoid arthritis of the cervical spine. An analysis of 333 cases. Ann Rheum Dis 25:120-126, 1966

8. Crawford CH III, Carreon LY, Djurasovic M, Glassman SD: Lumbar fusion outcomes in patients with rheumatoid arthritis. Eur Spine J 17:822-825, 2008

9. Crockard HA: Surgical management of cervical rheumatoid problems. Spine (Phila Pa 1976) 20:2584-2590, 1995

10. Dreyer SJ, Boden SD: Natural history of rheumatoid arthritis of the cervical spine. Clin Orthop Relat Res (366):98-106, 1999

11. Glassman SD, Hamill CL, Bridwell KH, Schwab FJ, Dimar JR, Lowe TG: The impact of perioperative complications on clinical outcome in adult deformity surgery. Spine (Phila Pa 1976) 32:2764-2770, 2007

12. Hamilton JD, Gordon MM, McInnes IB, Johnston RA, Madhok R, Capell HA: Improved medical and surgical management of cervical spine disease in patients with rheumatoid arthritis over 10 years. Ann Rheum Dis 59:434-438, 2000

13. Härle P, Straub RH, Fleck M: Perioperative management of immunosuppression in rheumatic diseases-what to do? Rheumatol Int 30:999-1004, 2010

14. Helliwell PS, Zebouni LN, Porter G, Wright V: A clinical and radiological study of back pain in rheumatoid arthritis. $\mathbf{B r} \mathbf{J}$ Rheumatol 32:216-221, 1993

15. Heywood AW, Meyers OL: Rheumatoid arthritis of the thoracic and lumbar spine. J Bone Joint Surg Br 68:362-368, 1986

16. Inaoka M, Tada K, Yonenobu K: Problems of posterior lumbar interbody fusion (PLIF) for the rheumatoid spondylitis of the lumbar spine. Arch Orthop Trauma Surg 122:73-79, 2002

17. Kawaguchi Y, Matsuno H, Kanamori M, Ishihara H, Ohmori K, Kimura T: Radiologic findings of the lumbar spine in patients with rheumatoid arthritis, and a review of pathologic mechanisms. J Spinal Disord Tech 16:38-43, 2003

18. Kim DH, Hilibrand AS: Rheumatoid arthritis in the cervical spine. J Am Acad Orthop Surg 13:463-474, 2005

19. Lawrence JS, Sharp J, Ball J, Bier F: Rheumatoid arthritis of the lumbar spine. Ann Rheum Dis 23:205-217, 1964

20. Lawrence RC, Helmick CG, Arnett FC, Deyo RA, Felson DT, Giannini EH, et al: Estimates of the prevalence of arthritis and selected musculoskeletal disorders in the United States. Arthritis Rheum 41:778-799, 1998

21. Lehtinen JT, Kaarela K, Belt EA, Kautiainen HJ, Kauppi MJ, Lehto MUK: Incidence of glenohumeral joint involvement in 
seropositive rheumatoid arthritis. A 15 year endpoint study. J Rheumatol 27:347-350, 2000

22. Lehtinen JT, Kaarela K, Ikävalko M, Kauppi MJ, Belt EA, Kuusela PP, et al: Incidence of elbow involvement in rheumatoid arthritis. A 15 year endpoint study. J Rheumatol 28:70-74, 2001

23. Makino T, Kaito T, Fujiwara H, Yonenobu K: Lumbar scoliosis in rheumatoid arthritis: epidemiological research with a DXA cohort. Spine (Phila Pa 1976) 38:E339-E343, 2013

24. Mirza SK, Deyo RA, Heagerty PJ, Konodi MA, Lee LA, Turner JA, et al: Development of an index to characterize the "invasiveness" of spine surgery: validation by comparison to blood loss and operative time. Spine 33:2651-2662, 2008

25. Morizono Y, Sakou T, Kawaida H: Upper cervical involvement in rheumatoid arthritis. Spine (Phila Pa 1976) 12:721725,1987

26. Moskowitz A: Scoliosis and juvenile rheumatoid arthritis. A case report of surgical treatment. Spine (Phila Pa 1976) 15:46-49, 1990

27. Neva MH, Kaarela K, Kauppi M: Prevalence of radiological changes in the cervical spine - a cross sectional study after 20 years from presentation of rheumatoid arthritis. $\mathbf{J}$ Rheumatol 27:90-93, 2000

28. Paimela L, Laasonen L, Kankaanpää E, Leirisalo-Repo M: Progression of cervical spine changes in patients with early rheumatoid arthritis. J Rheumatol 24:1280-1284, 1997

29. Pellicci PM, Ranawat CS, Tsairis P, Bryan WJ: A prospective study of the progression of rheumatoid arthritis of the cervical spine. J Bone Joint Surg Am 63:342-350, 1981

30. Ranawat CS: Surgical management of the rheumatoid hip. Rheum Dis Clin North Am 24:129-141, 1998

31. Rawlins BA, Girardi FP, Boachie-Adjei O: Rheumatoid arthritis of the cervical spine. Rheum Dis Clin North Am 24:55-65, 1998

32. Rombouts JJ, Rombouts-Lindemans C: Scoliosis in juvenile rheumatoid arthritis. J Bone Joint Surg Br 56B:478-483, 1974

33. Sakai T, Sairyo K, Hamada D, Higashino K, Katoh S, Takata Y, et al: Radiological features of lumbar spinal lesions in patients with rheumatoid arthritis with special reference to the changes around intervertebral discs. Spine J 8:605-611, 2008

34. Santavirta S, Slätis P, Kankaanpää U, Sandelin J, Laasonen E: Treatment of the cervical spine in rheumatoid arthritis. J Bone Joint Surg Am 70:658-667, 1988

35. Scott DL, Symmons DPM, Coulton BL, Popert AJ: Long- term outcome of treating rheumatoid arthritis: results after 20 years. Lancet 329:1108-1111, 1987

36. Sculco TP: The knee joint in rheumatoid arthritis. Rheum Dis Clin North Am 24:143-156, 1998

37. Sims-Williams H, Jayson MI, Baddeley H: Rheumatoid involvement of the lumbar spine. Ann Rheum Dis 36:524-531, 1977

38. Zimmerman RM, Mohamed AS, Skolasky RL, Robinson MD, Kebaish KM: Functional outcomes and complications after primary spinal surgery for scoliosis in adults aged forty years or older: a prospective study with minimum two-year follow-up. Spine (Phila Pa 1976) 35:1861-1866, 2010

\section{Author Contributions}

Conception and design: Kebaish, Mesfin, Kostuik, Lemma. Acquisition of data: Mesfin, El Dafrawy, Jain, Hassanzadeh. Analysis and interpretation of data: Mesfin, El Dafrawy, Jain, Hassanzadeh. Drafting the article: Kebaish, Mesfin, Kostuik, Lemma. Critically revising the article: Kebaish, Mesfin.

Reviewed submitted version of manuscript: all authors. Approved the final version of the manuscript on behalf of all authors: Kebaish. Statistical analysis: Mesfin, Jain. Administrative/technical/material support: El Dafrawy, Jain, Hassanzadeh. Study supervision: Kebaish.

\section{Supplemental Information \\ Proceedings}

This study was presented at the International Meeting on Advanced Spine Techniques held in Copenhagen, Denmark, July 13-16, 2011, and the Scoliosis Research Society Annual Meeting held in Louisville, KY, September 14-17, 2011.

\section{Current Affiliation}

Dr. Mesfin: Department of Orthopaedic Surgery, University of Rochester, Rochester, NY.

\section{Correspondence}

Khaled M. Kebaish, c/o Rachel Box, Editorial Services, Department of Orthopaedic Surgery, The Johns Hopkins University/Johns Hopkins Bayview Medical Center, 4940 Eastern Ave., A665, Baltimore, MD 21224-2780. email: rbox1@jhmi. edu. 